\title{
Uma ideia destemida ou um sonho a ser construído? Anísio Teixeira e o projeto de educação brasileira
}

\section{A dreaming idea or a dream to be built? Anísio Teixeira and the Brazilian education project}

\section{¿Una idea valiente o un sueño a ser construido? Anísio Teixeira y el proyecto de educación brasileña}

Kamila Gusatti Dias ${ }^{1}$

Kênia Guimarães Furquim Camargo ${ }^{1}$

Maria Zeneide Carneiro Magalhães de Almeida ${ }^{1}$

DOI: http://dx.doi.org/10.20435/serie-estudos.v26i56.1420

\begin{abstract}
Resumo: O presente texto tem como escopo evidenciar aspectos relevantes sobre a vida e a obra de Anísio Teixeira (1900-1971) e, sobretudo, investigar os momentos decisivos da sua biografia, suas motivações como educador, bem como os aspectos da sua apropriação das ideias de John Dewey e a atualidade das suas concepções para pensar a educação brasileira contemporânea. O aporte teórico está pautado em uma pesquisa de cunho bibliográfico, a qual pode nos oferecer subsídios para compreendermos a trajetória do pensamento intelectual do autor para a realização de um projeto de educação brasileira. Anísio Teixeira foi um dos defensores de um movimento de entusiasmo pela educação e de um otimismo pedagógico, liderado pelos intelectuais que defendiam a expansão da escola pública, gratuita e laica. A mola propulsora da obra anisiana no campo da educação estava pautada na educação como um direito de todos, não apenas das elites e jamais como um privilégio para poucos. Esperamos que essa inspiração denominada aqui por ideia destemida ou talvez um sonho construído por ele possa nos impulsionar a acreditar em uma educação pública de fato igualitária, democrática e, sobretudo, de qualidade. Anísio Teixeira sonhou e, no seu sonho, viu uma escola eficiente para o povo brasileiro, e é com esse propósito que ainda lutamos por ela.
\end{abstract}

Palavras-chave: Anísio Teixeira; vida; obra.

Abstract: The purpose of this text is to highlight relevant aspects of the life and work of Anísio Teixeira (1900-1971) and especially to investigate the decisive moments of his biography, his motivations as an educator, as well as the aspects of his appropriation of John's ideas Dewey and the actuality of his conceptions to think contemporary Brazilian education. The theoretical

\footnotetext{
${ }^{1}$ Pontifícia Universidade Católica de Goiás (PUC-GO), Goiânia, Goiás, Brasil.
} 
contribution is based on bibliographic research, which can offer us subsidies to understand the trajectory of the author's intellectual thought for the realization of a Brazilian education project. Anísio Teixeira was one of the proponents of a movement of enthusiasm for education and a pedagogical optimism, led by the intellectuals who advocated the free and secular public school expansion. The driving force of the Anisian work in the field of education was based on education as a right of all, not only of the elites, and never as a privilege for the few. We hope that this inspiration, known here as a fearless idea or perhaps a dream built by it, can propel us to believe in a truly equal, democratic, and, above all, quality public education. Anísio Teixeira dreamed and, in his dream, he saw an efficient school for the Brazilian people and it is for this purpose that we still fight for it.

Keywords: Anísio Teixeira; life; work.

Resumen: El presente texto tiene como objetivo evidenciar aspectos relevantes sobre la vida y la obra de Anísio Teixeira (1900-1971) y, sobre todo, investigar los momentos decisivos de su biografía, sus motivaciones como educador, así como los aspectos de su apropiación de las ideas de John Dewey y la actualidad de sus concepciones para pensar la educación brasileña contemporánea. El aporte teórico está pautado en una investigación de cuño bibliográfico, la cual nos puede ofrecer subsidios para comprender la trayectoria del pensamiento intelectual del autor para la realización de un proyecto de educación brasileña. Anísio Teixeira fue uno de los defensores de un movimiento de entusiasmo por la educación y un optimismo pedagógico, dirigido por los intelectuales que abogaron por la expansión de la escuela pública libre y secular. La fuerza impulsora del trabajo anisiano en el campo de la educación se basó en la educación como un derecho de todos, no solo de las élites y nunca como un privilegio para unos pocos. Esperamos que esta inspiración, conocida aquí como una idea intrépida o tal vez un sueño construido por ella, pueda impulsarnos a creer en una educación pública verdaderamente igualitaria, democrática y, sobre todo, de calidad. Anísio Teixeira soñó y, en su sueño, vio una escuela eficiente para el pueblo brasileño, y es por este motivo que aún luchamos por ella.

Palabras clave: Anísio Teixeira; vida; trabajo.

\section{INTRODUÇÃO}

Nosso ponto de partida neste trabalho foi um trecho da carta escrita por Anísio Teixeira a Monteiro Lobato, em janeiro do ano de 1947, quando declara que "[...] os sonhos não se realizam sem que primeiro se armem os andaimes. E uma construção em andaimes pede imaginação e amor para ser compreendida" (VIANA; FRAIZ, 1986, p. 104 apud NUNES, 1991, p. 33).

Esse trecho da carta nos chama atenção e nos faz mergulhar de modo despretensioso em sua biografia e em sua trajetória marcante na contribuição da educação brasileira. Ao ler esse trecho e saber que Anísio Spínola Teixeira (19001971) foi um dos defensores de um movimento de entusiasmo pela educação e de um otimismo pedagógico, liderado pelos intelectuais que defendiam a expansão da 
escola pública, gratuita e leiga, nós nos debruçamos nos estudos de sua biografia e também em algumas obras, a fim de perceber os "sonhos" ansiados por Anísio em todo seu percurso em busca de uma nova educação brasileira.

A montagem dos andaimes foi o alicerce a fim de construir novas ideias pedagógicas em busca de uma modernização da escola brasileira. Assim, indagamos: de onde vinha tanta força para o enfrentamento dos desertos pelos quais Anísio teve de passar, para realizar o sonho de um país mais humano e solidário? Quem foi esse homem à frente do seu tempo e o que fez suscitar, por pensar a educação brasileira na atualidade? Essas questões nos incita e nos faz um convite para essa reflexão.

Muitos autores se debruçaram em suas obras e no estudo de sua biografia em busca dessas respostas, uma delas foi a autora Clarice Nunes, estudiosa da obra anisiana, que publicou no ano de 2010, junto ao Ministério da Educação (MEC) e à Organização das Nações Unidas para a Educação, a Ciência e a Cultura (UNESCO), o livro Anísio Teixeira, pertencente à Coleção Educadores MEC. Foi por meio dessa obra que nos aproximamos da vida desse intelectual brasileiro, um homem de sólida formação que, diante do "atraso" cultural do país e da caótica situação do ensino que assolava o fim do século XIX e início do XX, preocupou-se em reconstruir a nação, acreditando ser pela renovação educacional o caminho ou uma das alternativas para o sucesso e na busca por uma democracia no país.

Aos seus 24 anos, Anísio marcou sua entrada na vida pública, no ano de 1924, quando recebeu o convite para ocupar o posto de diretor da Instrução Pública do Estado da Bahia. Nessa conjuntura, realizou a reforma da instrução pública nesse estado durante os anos de 1924-1929 no governo de Francisco Marques de Góes Calmon, e, dali em diante, surgia a ideia destemida e/ou um sonho a ser construído em busca de um novo projeto para a educação brasileira.

Simultaneamente, ao iniciar-se no cargo de inspetor-geral da Instrução da Bahia, Anísio lançava-se na carreira docente, nomeado professor de Filosofia da Educação da Escola Normal de Salvador, o que o fez sofrer severas críticas dos oposicionistas, principalmente porque havia eliminado a vitaliciedade do magistério e, também, porque as ideias que buscou colocar em prática "representavam uma agressão àquela sociedade agrícola e oligárquica" (FILHO, 2008, p. 47). Dessa experiência e dentre outras vividas por Anísio Teixeira, sua docência foi sendo influenciada e, segundo Gouvêa (2009, p. 432), "a centralidade da formação de 
professores na vida-obra de Anísio revela, muito além de um eloquente discurso, um compromisso", foi uma preocupação constante para Anísio.

Com a morte de seu pai, Anísio buscou trabalho no Rio de Janeiro, com apoio do então ministro Francisco Campos, e, antes de atuar como professor do Instituto de Educação do Rio de Janeiro² e de assumir a Diretoria do Departamento da Instrução Pública carioca, buscou um aprimoramento intelectual, entre os anos de 1927 e 1928; por dez meses, estudou no Teachers College, da Universidade de Colúmbia, Nova lorque. Recebeu o título de Master of Arts, foi aluno de William Heard Kilpatrick, William James, Bertrand Russel, Wells, Thorndike, além de John Dewey. Nessa viagem para seus estudos, houve um maior envolvimento entre Anísio e a Filosofia, a qual contribuiu profundamente nas reformas dos sistemas de ensino e na publicação dos seus livros e artigos. Esse aculturamento americano foi imprescindível na carreira e na filosofia de Anísio Teixeira.

A cena social dos Estados Unidos, sobretudo vista da Universidade, que foi o campo onde ele pensou e trabalhou, reforçou-lhe a fé democrática e republicana, ampliou-lhe as perspectivas futuras da obra educacional, ofereceu-lhe a motivação de um pensamento organizador que se arrematava por uma concepção do mundo naturalista e científico. O ambiente vivido na América, os contatos intelectuais e pessoais, a atmosfera antidogmática do ensino, as aberturas de pesquisa e da especulação filosófica, tudo isto conduziu-o a conceber e interpretar o mundo fora das quatro linhas da mística jesuítica em que se enleara. Sentiu-se realmente libertado, não porque houvesse adquirido, em lugar das velhas certezas definitivas, novas certezas definitivas, mas porque aprendera um processo, um método diferente de pensar e colocar problemas. (VIANA FILHO, 2008, p. 36).

Nesse ínterim, o jovem preceptor pode se aproximar de vários sistemas públicos de educação, até então desconhecidos da sua experiência. Durante esse período, mergulhou com profundidade pela obra do filósofo americano John Dewey, a partir da qual, de maneira incisiva, passou a delinear todo seu decurso intelectual. Nunes (2000) lança luz sobre a nova literatura pedagógica e o novo sistema de educação conhecido por Anísio pelas suas viagens feitas aos Estados Unidos e pela Europa, o que o fez distanciar da sua realidade, impactando-se.

\footnotetext{
${ }^{2}$ Constituído, em 1932, pela integração do Jardim de Infância, Escolas Primária, Secundária e de Professores, o Instituto de Educação elevava a formação para magistério ao nível superior no Brasil, por meio do Decreto 3.810, de 19 de março de 1932, assinado pelo próprio Anísio.
} 
Em oposição à cultura, à organização, à competência docente dos colégios nos quais estudara, deparou - em sua cidade e em seu Estado natal - com a pobreza de recursos humanos e materiais, a dispersão e a desarticulação dos serviços educativos, o despreparo do professor, a imoralidade, a corrupção e a acomodação dos poderes públicos, alimentando a ineficiência da máquina estatal. (NUNES, 2000, p. 156).

Anísio se vislumbrava com a modernidade pedagógica que vivenciara em suas viagens e, com isso, começou a planejar ideias destemidas e/ou um sonho que precisava ser construído na educação brasileira. Destarte, fez com que Anísio Teixeira se apropriasse das ideias de Dewey e voltasse para o Brasil a fim de propor uma inovação na educação brasileira, embasada nas ideias revolucionárias daqueles países.

Ao longo de sua gestão pública, assumiu outros cargos, a saber: no ano de 1925, a função na direção da Educação e Saúde da Bahia. Nessa perspectiva, recebe outros convites, como o de 1931, para assumir como diretor-geral da Instrução Pública, no Rio de Janeiro, à época, Distrito Federal. Mais tarde, já no ano de 1947, agora no Estado da Bahia, outro desafio educacional lhe é dado: a pasta como secretário de Educação e Saúde da Bahia.

Ao assumir o cargo, inicialmente fez um projeto de lei, a fim de renovar e expandir o ensino na Bahia, muitas reformas e uma grande revolução, o que, para Viana Filho (2008, p. 29), "não se tratava, portanto, de 'alfabetizar em massa', mas sim de educar maior número de crianças, para que adquirissem o maior número de conhecimentos na melhor escola permitida. E isso era inovação na Bahia”.

Nesse ponto de vista, Cavaliere evidencia que antes da viagem de Anísio Teixeira aos Estados Unidos, no ano de 1927, duas peças legislativas foram defendidas por ele, a saber - a Reforma da Instrução Pública da Bahia e o decreto que aprovava o Regulamento do Ensino Primário e Normal; ambos apresentavam em suas propostas "[...] a influência de ideias renovadoras [...], ainda que predominasse o sentido republicano democratizador" (CAVALIERE, 2010, p. 250).

Nesse ínterim, no Estado do Rio de Janeiro, em outubro de 1924, surgiu a Associação Brasileira de Educação ${ }^{3}(\mathrm{ABE})$, por intermédio de 13 intelectuais da elite brasileira carioca. O objetivo da ABE era organizar um "partido de ensino",

\footnotetext{
${ }^{3}$ A Associação Brasileira de Educação nasce com um claro objetivo: tirar das mãos do Congresso a discussão educacional e criar um programa de ação nacional para a educação.
} 
capaz de firmar-se como "órgão apolítico, destinado a congregar os interessados na causa da educação, independentemente de doutrinas filosóficas ou religiosas ou de posições políticas" (SAVIANI, 2013, p. 229), com o propósito do qual poder-se-ia ouvir a voz e conhecer os interesses e as ambições de um determinado grupo que estava disposto a discutir as mudanças no sistema educacional brasileiro, o que, antes, estava subvencionado apenas ao Estado.

No ano de 1931, acontece também, no Rio de Janeiro, a IV Conferência Nacional de Educação, da qual Getúlio Vargas ${ }^{4}$ e o então ministro da Educação e Saúde Pública, Francisco Campos, incentivaram os educadores a elaborar "as bases de uma nova política educacional para ser guiadas as ações do governo em todo o país" (SAVIANI, 2013, p. 230). Esses educadores, entre eles, Anísio Teixeira, líder e mentor do Manifesto, denominados de pioneiros da Educação Nova, tinham fortes razões para acreditar que a adoção dos princípios pedagógicos professados pela Escola Nova seria o antídoto definitivo para os problemas educacionais brasileiros.

Concomitantemente, o governo buscava uma parceria para legitimar sua política educacional, e o Manifesto, um documento que aliava as novas ideias e os novos princípios educacionais, foi visto como um instrumento de luta em prol da reconstrução da educação no país. Nesse Manifesto, a espinha dorsal e ideológica estava alicerçada nas ideias de Anísio Teixeira; ele estava presente e seria a peça fundamental na sua aplicação, segundo Viana Filho (2008).

Já no governo Getúlio Vargas (1951-1954), Anísio Teixeira assumiu como diretor do Instituto Nacional de Estudos Pedagógicos (INEP), órgão do Ministério da Educação e Cultura, e, posteriormente, no governo de João Café Filho (1954 a 1955) e no de Juscelino Kubitschek de Oliveira (1956-1961). Percebemos, por meio dos cargos ocupados por Anísio, sua ascensão na gestão pública da educação.

Entretanto, de acordo com Saviani (2013), Anísio teve vários ensejos para se idealizar como político, mas sua decisão pelo magistério foi prioritária. O primordial em seu empreendimento na gestão pública era a reforma da sociedade pelo viés da educação, tornando-a como fundamento desse processo de inovação e da modernização da sociedade. A mola propulsora da obra anisiana no campo

\footnotetext{
${ }^{4}$ Nesse momento, chefe do governo provisório resultante da Revolução de 1930.
} 
da educação estava pautada na educação como um direito de todos, não apenas das elites e jamais como um privilégio para poucos.

Dessa maneira, como a pesquisa histórica nos permite reconstruir objetos de estudo sob outros vieses, empreendemos no estudo da sua biografia com outros olhares.

\section{ANÍSIO, SUA VIDA PESSOAL E INTELECTUAL}

Na cidade de Caetité, no sertão baiano, nasceu no dia 12 de julho de 1900, em um amplo sobrado localizado em frente à Praça Central e à Igreja Católica, o menino Anísio. Filho de um dos maiores proprietários de terra da região da Bahia, Deocleciano Pires Teixeira, médico e também um político influente, e de dona Anna Spínola Teixeira, a alma boa da cidade baiana.

Sua formação primária se deu inicialmente pelos cuidados da professora dona Maria Teodolina das Neves Lobão e também pela sua tia Priscila Spínola, sendo posteriormente matriculado, no ano de 1911, no Instituto São Luiz Gonzaga, escola fundada por jesuítas, na cidade de Caetité, para cursar o ginásio. Lá teve uma sólida formação, com comportamento e hábitos induzidos pelo local, apropriando-se dos valores morais e éticos, segundo os pressupostos da formação jesuítica, pautado nas experiências de seus professores, na maioria padres. Transferiu-se para Salvador no ano de 1914, a fim de cursar o ensino secundário no também colégio católico e jesuítico Antônio Vieira. Nesse colégio, Anísio aprimorou seus conhecimentos, e o contato com outros professores o fez "aprender a se vestir, comportar-se, organizar-se, a suportar privações e superar obstáculos” (SILVA, 2015, p. 14153).

Silva (2015) afirma que o corpo docente do Colégio Antônio Vieira, em sua maioria formado por clérigos, genuinamente incitaram seu interesse vocacional. Entretanto, entre seguir sua vocação ao sacerdócio ou se enveredar pela política, optou, por exigência de seu pai, por cursar seus estudos jurídicos na faculdade de Ciências Jurídicas e Sociais da Universidade do Rio de Janeiro, no ano de 1922, mesmo com todas as influências de seu pai, um coronel do Nordeste; o berço de Anísio, portanto, era de uma família oligárquica.

Sua intensa relação com os padres jesuítas fizeram com que os laços se estreitassem com os padres da Companhia de Jesus, e, para Nunes (2010, p. 14), "Anísio poderia ser um instrumento no sentido de ampliar a influência da Igreja 
dentro da estrutura estatal". A partir dessa aproximação com a Igreja Católica e da forte influência política da família Teixeira, o favorecimento dos grupos políticos locais tornar-se-ia um jogo de interesses.

A vocação de Anísio foi permeada de muita indecisão, o que podemos perceber nos argumentos de Nunes (2010):

[...] o catolicismo parecia uma verdade tão completa e tão grandiosa que se disporia a dedicar sua vida por inteiro para defendê-la. Aguardava a manifestação da vontade divina e o consentimento dos pais para ingressar no noviciado. Dos 19 aos 22 anos, Anísio oscilou entre seguir a vida religiosa ou a vida secular. Aguardava o consentimento dos pais para realizar o que percebia como sua vocação sacerdotal, mas a graça não veio. O pai de Anísio via nele um magistrado nato, seu sucessor natural, futuro patriarca familiar. Padre Cabral via nele uma vocação para o sacerdócio e, pelos seus talentos, alguém destinado a ocupar postos importantes na hierarquia eclesiástica. Espremido entre as aspirações da autoridade paterna e as da autoridade religiosa acabou retardando seu ingresso ao sacerdócio e abdicando da carreira de político profissional. (NUNES, 2010, p. 14).

Ao lançar luz sobre as evidências de que Anísio não optou pelo sacerdócio tampouco pela carreira na política, nós nos perguntamos: o que o fez decidir pela carreira do magistério, haja vista que não era professor? Apoiados no pensamento de Nunes (2000), podemos compreender melhor a sua escolha:

[...] Anísio não nasceu educador. Tornou-se educador num processo laboriosamente construído, lapidado no diálogo com os diversos educadores que dentro dele transitaram, na intensa experiência dos exercícios espirituais realizados na juventude, nas reflexões suscitadas pelas viagens internacionais, nas fiéis amizades, como a que manteve com Monteiro Lobato e Fernando de Azevedo, na experiência da gestão pública da educação. (NUNES, 2000, p. 155).

Um de seus biógrafos, Luís Viana Filho (2008, p. 28) atesta que “Anísio tinha os olhos abertos para o mundo que pressentia surgir" e a carreira docente foi a opção feita por Anísio, em meados dos anos de 1920, nesse período em que "a educação não estava ainda caracterizada profissionalmente e, assim como hoje, gozava de muito pouco reconhecimento social (SAVIANI, 2013, p. 218). Ainda se tinha bastante por fazer, ao passo de que a ideia destemida e/ou sonho a ser construído por Anísio Teixeira fizesse-o enveredar-se nos desertos que teria de enfrentar para vencer essas rupturas. 
Dessa forma, o intelectual e gestor Anísio Teixeira se empenhava na montagem dos seus andaimes, em busca da sua ideia destemida e/ou um sonho a ser construído por ele - uma escola pública para todos os brasileiros.

O pensamento anisiano refletia a influência dos cursos e contatos no Brasil e fora do país que apontariam um novo rumo para Anísio, que, do ponto de vista intelectual, revelar-se-ia um "outro" Anísio. Um Anísio que bebeu em novas fontes uma nova filosofia: o progressivismo de Dewey (GOUVÊA, 2009). Para Nunes (2010, p. 19), "o pragmatismo deweyano forneceu-Ihe um guia teórico que combateu a improvisação e o autodidatismo, permitiu-lhe operacionalizar uma política e criar a pesquisa educacional no país".

Deve-se considerar, ainda, quão árdua e difícil é a missão de distanciar a docência de Anísio e seu envolvimento na política educacional com suas atividades como escritor. Anísio passou por uma grande transformação intelectual, adotou as ideias pragmatistas de John Dewey, em resposta ao seu inquietamento diante dos valores do catolicismo jesuíta já internalizado por ele desde sua infância. As respostas que buscava contra a ruptura de dogmas ele encontrou na filosofia deweyana:

[...] a qual propunha o permanente contato entre a teoria e a prática e colocava a atividade do aluno como elemento central da aprendizagem. Teixeira compreendeu que a pedagogia Deweyana tinha bases em uma filosofia que assumia papel ativo na vida social e política e buscava assumir a responsabilidade de contribuir para o desenvolvimento da democracia e para a formação de cidadãos dotados de uma mentalidade moderna e científica, aberta à mudança e à cooperação. (BORTOLOTI; CUNHA, 2010, p. 4).

Anísio adota Dewey como sua viga mestre, de quem seria o primeiro tradutor no Brasil, e dessa maneira teria de sobrepor os valores que tinha imbuídos pelo catolicismo, vivenciando, assim, sua primeira ruptura, da qual teria de perpassar: o rompimento com a fé.

\section{A DILIGÊNCIA CONTRA O ANIQUILAMENTO INTELECTUAL DE ANÍSIO TEIXEIRA}

Anísio apresentava um perfil de intelectual com o bojo de suas ações voltadas para a construção de uma sociedade mais justa, igualitária e moderna. Via a educação como intercessora. 
O legado deixado por Teixeira apresentava ainda uma expressiva contribuição acerca da estruturação do sistema brasileiro educacional. O sonho idealizado por ele era a concretização de um sistema educativo de qualidade e, acima de tudo, democrático. Dessa forma, a sociedade tornar-se-ia mais igualitária.

Com base nesses a pontamentos, Bertoletti e Coelho (2013) atestam a preocupação de Anísio diante dos problemas de ordem social e da busca de soluções na formação educacional dos sujeitos. Para os autores, Anísio

Retratou, em suas obras, a necessidade de se formar um sujeito com valores voltados para o saber, o progresso, a liberdade e a democracia, já que, segundo ele, estas características consistiam em uma necessidade nacional. (BERTOLETTI; COELHO, 2013, p. 2).

Compreender a situação real do sistema educacional brasileiro e equipará-lo a um "problema nacional" era, para Anísio, uma sucessão em que todos os outros problemas do país estariam solucionados. Para tanto, ele se propôs a solucioná-los, mas os embates sofridos para a construção desses andaimes foram muitos.

Nesse sentido, Anísio inicia uma busca por respostas às suas inquietações, o "baiano americanizado" já não era mais o mesmo. Voltou da Europa e estava cada vez mais longe dos dogmas religiosos, ao ponto de questionar-se: "Por que não servir a Deus no mundo?" (NUNES, 2010, p. 15). Destarte, sua renúncia com o catolicismo foi anunciada, Anísio iniciou "a travessia do seu primeiro deserto: o deserto da fé" (NUNES, 2000, p. 156).

Militante do movimento católico, Anísio abdicou de toda a formação religiosa de base jesuítica, ao surgimento dos movimentos de matriz nacionalista que, em contraposição ao regime político da oligarquia latifundiária e da Igreja conservadora, lutavam por um novo sistema jurídico e político.

Os apontamentos de Pereira (2014) são contundentes e exemplificam essa situação, diante do benefício que as famílias da elite obtinham no Brasil:

[...] é a questão do monopólio da Igreja na educação. Foi uma luta incessante que o consumiu por toda vida, pois a ideia que os bispos tinham no país era a de que: a família tinha que optar por qual escola o seu filho seria educado, e não uma obrigação do Estado em sua função democrática e emancipadora, conforme proposto por Anísio. Além de cuidar da educação dos filhos da oligarquia latifundiária, a Igreja rezava missa para eles e reforçava sua posição em defesa dos interesses particulares, agravando o abismo de classe 
existente entre o povo ágrafo, miscigenado e escravizado, e a elite dirigente do país. (PEREIRA, 2014, p. 38-9).

Anísio se opunha a essa situação e, logo depois do regresso da sua viagem da Europa, começou o seu processo de inquietação e estranhamento ao ver os passos que o Brasil caminhava, com "[...] os problemas típicos da educação no Brasil como a corrupção, a ausência do poder público, o despreparo do professorado, começando assim uma hercúlea batalha em busca de uma educação sem privilégios" (PEREIRA, 2014, p. 36).

A Igreja se opunha às ideias modernizantes de Anísio e, em objeção, elaborou um Manifesto idealizado por Bispos da Igreja Católica em oposição às ideias anisianas, em veemência para tentar afastar Anísio do cargo que ocupava no Ministério da Educação e Cultura, haja vista que o processo de restruturação do sistema educacional brasileiro já havia sido implantado por Teixeira.

Naquela conjuntura, a Igreja Católica, de maneira contundente, partiu para a disputa política aberta, pressionando o governo federal, articulando-se com o Parlamento e buscando mobilizar a opinião popular acerca da legitimidade de sua defesa da escola privada; a Igreja argumentou defender a liberdade de a família escolher a educação para os seus filhos, trazendo o elemento dogmático de um povo católico que, supostamente, por livre iniciativa, não confiaria a educação dos seus filhos a uma escola estatal e laica. A reação dos defensores da escola pública foi proporcional, gerando manifestações organizadas e levando a imprensa à discussão sobre o destino da educação no país.

Um dos principais argumentos utilizados contra Anísio era o fato de ele, supostamente, estar pregando o monopólio estatal do ensino, querendo "abolir" do sistema educacional as escolas privadas. Contudo, ao se falar em educação para todos, isso não significava, necessariamente, monopólio estatal da educação, mas assegurar a educação para todos, fosse via Estado - este, aliás, obrigado constitucionalmente a fazê-lo - ou por meio da iniciativa privada. Anísio desconsiderava que a escolarização de todos os cidadãos fosse uma utopia, mas entendia-a como dever legal:

O problema da educação para todos é um problema legal, isto é, de singelo cumprimento do preceito constitucional. Desde que estabelecemos que a educação é um direito - e foi o que fizemos em nossa Constituição - a 
expansão da educação para todos se fez um dever do Estado no Brasil. (TEIXEIRA, 1994, p. 7).

Outro dado interessante é o fato de Anísio julgar que a educação não podia ser um privilégio, assim, não colaborava no desenho do novo país que a nova sociedade necessitava. Sendo um privilégio, a educação torna-se estética, servindo apenas para diferenciar os educados dentro de uma massa de "deseducados".

Naquela ocasião, Anísio Teixeira já havia se distanciado totalmente de suas inclinações religiosas e assumido posições renovadoras e modernizantes na área educacional, contrárias, até mesmo, ao ensino religioso em escolas públicas, e com isso principiou-se uma resistência entre os conservadores, ligados à Igreja, e os liberais.

Em meados da década de 1930, Anísio e seus colaboradores, entre eles, Fernando de Azevedo e Lourenço Filho, aproximaram-se da Aliança Nacional Libertadora $(\mathrm{ANL})^{5}$ e, com o apoio do então prefeito do Distrito Federal - Pedro Ernesto -, Anísio Teixeira foi seu secretário de Educação e Cultura, promovendo mudanças na estrutura educacional da cidade e impulsionando a criação de novos estabelecimentos de ensino na cidade. Em uma dessas iniciativas, criou a Universidade do Distrito Federal (UDF), da qual também foi reitor, ocasionando uma objeção do ministro da Educação Gustavo Capanema e de líderes do pensamento católico conservador, que dirigiram campanhas contra Anísio, acusando-o severamente de populista, ateu e estatizante.

Anísio Teixeira perdeu seu cargo de reitor e de secretário, assim como Pedro Ernesto, a mando de uma propaganda de ação desencadeada por Getúlio Vargas. E, como era contrário por princípio à utilização da violência na luta política, foi atingido pelas medidas repressivas, pouco propícias às suas atividades modernizadoras no campo da educação, sendo substituído por Francisco Campos.

Nas palavras de Nunes (2010, p. 26), "tornara-se um trabalhador gasto e desmoralizado pelo fascismo brasileiro". Todos esses fatos fizeram com que Anísio atravessasse seu segundo deserto, a saber: o deserto da solidão.

\footnotetext{
${ }^{5}$ A ANL era uma frente política que reunia diversos setores de esquerda em torno de uma plataforma de combate ao fascismo e ao imperialismo. Com certa frequência, Anísio escrevia artigos em A Manhã, jornal oficioso da ANL. Apesar de contrário às ações políticas violentas, acabou sendo acusado de envolvimento no levante comunista promovido por essa organização, em novembro de 1935.
} 
Nesse contratempo, a ditadura militar se instaurava no país e trazia, com ela, o silenciamento de Anísio. Sua voz foi emudecida pela ditadura e sua volta para a Bahia seria seu aconchego. Lamentando haver deixado a Bahia, acrescentava: "Só há um lugar, no mundo, para se envelhecer: é a nossa Bahia. Como a Bahia, na sua admirável estagnação, evita-nos a dolorosa impressão que tenho sentido aqui no Rio!" (VIANA FILHO, 2008, p. 146).

Entre os anos de 1937 e 1945, um período em que o pensamento democrático brasileiro esteve sufocado, Anísio Teixeira permanece na Bahia e dedica-se a atividades empresariais, com a exploração e exportação de manganês, calcário e cimento, a comercialização de automóveis e a tradução de livros para a Companhia Editora Nacional.

Anísio foi submetido a um silêncio que o fez refletir acerca das questões sociais e de que "caberia ao Estado ser o principal promotor da escolarização e difusor da cultura junto às classes populares" (NUNES, 2010, p. 27). Suas ideias foram emudecidas e "os tocos de sua obra, como profetizara Lobato, ficaram enterrados para brotar de novo" (NUNES, 2010, p. 26).

Já no ano de 1946, vivendo em Londres e Paris, tornou-se conselheiro de educação superior da recém-criada UNESCO, órgão das Nações Unidas voltado para a educação, a ciência e a cultura. No ano seguinte, ocupou a Secretaria de Educação e Saúde do governo baiano de Otávio Mangabeira, e foi o autor do anteprojeto do capítulo da Constituição Baiana que organizou conselhos municipais de educação em todo o estado e o Centro Educacional Carneiro Ribeiro, experiência pioneira de educação integral para jovens, que, mais tarde, serviu de modelo ao sistema educacional instalado em Brasília.

Em 1951, Anísio Teixeira deixou a Secretaria para, a convite do ministro da Educação Ernesto Simões Filho, tornar-se secretário-geral da Coordenação do Aperfeiçoamento de Pessoal de Nível Superior (CAPES). Nesse período, criou o Centro Brasileiro de Pesquisas Educacionais, com sedes regionais em São Paulo, Minas Gerais, Rio Grande do Sul, Bahia e Pernambuco, promovendo levantamentos da situação do ensino médio e elementar no país. Inaugurou também os centros nacionais de treinamento de pós-graduação, vinculados à CAPES, e lançou a campanha do livro didático e dos manuais de ensino.

Os ataques contra o aniquilamento intelectual de Anísio continuavam e, mesmo assim, ele continuou a receber manifestações de hostilidade por parte dos 
setores conservadores da Igreja Católica. Iniciava-se, nesse momento, o terceiro deserto por qual Anísio teria de passar: o deserto do ceticismo.

No ano de 1961, foi um dos principais idealizadores da Universidade de Brasília (UnB), da qual assumiu a reitoria, em 1962, quando seu reitor Darcy Ribeiro precisou se afastar para assumir a chefia do Gabinete Civil da Presidência da República. Com a instauração do governo militar, em 1964, Anísio Teixeira foi afastado do seu posto e aposentado compulsoriamente.

Nunes (2000) narra essa situação vivenciada outra vez por Anísio ante a insólita ação policial, agora diante da UnB, visto que já havia sofrido esse ataque dentro da UDF - no Rio de Janeiro -, quando funcionários e professores foram surpreendidos por tal anormalidade.

[...] tropas do Exército e da Polícia Militar de Minas Gerais tomaram de assalto o campus. Era a primeira de outras duas invasões que ocorreriam em 1965 e 1968. Os policiais procuraram armas. Inspecionaram minuciosamente a reitoria, a biblioteca, todos os escritórios em todos os setores. Prenderam professores e estudantes. [...] Essa agressão dispara uma campanha de difamação do trabalho até então desenvolvido com dificuldades, mas com muita dedicação e esperança, trabalho espezinhado por setores da imprensa que se aliaram ao regime militar sob os rótulos da irresponsabilidade, da indisciplina, da subversão, do atentado à doutrina da segurança nacional. Mais uma vez o Estado desqualificava a obra para que a sociedade lhe retirasse o apoio e, no enfraquecimento, a repressão pudesse agir: para aniquilar. [...] De novo a perseguição, a prisão de intelectuais. (NUNES, 2000, p. 8).

Anísio havia sido banido, excluído e desqualificado pelo Estado, a fim de que se desqualificasse "a obra para que a sociedade the retirasse o apoio e, no enfraquecimento, a repressão pudesse agir para aniquilar" (NUNES, 2010, p. 28). Mesmo assim, era penoso atravessar mais essa prova da vida e, nessa conjuntura, embarcou para os Estados Unidos e passou a lecionar como visiting scholar na Columbia University (1964), na New York University (1965) e a University of California (1966).

Aos seus setenta anos, Anísio encontrava-se saudável, inquieto, transbordando energia e vicissitude. Candidato à Academia Brasileira de Letras, trabalhava na Fundação Getúlio Vargas, no Rio de Janeiro. Mas, no dia 11 de março de 1971, Anísio deixou o local de trabalho para visitar o amigo Aurélio Buarque de Holanda e, como descreve o biógrafo de Anísio Luís Viana Filho: 
[...] Horas passaram sem que aparecesse em qualquer lugar. Seguiu-se a preocupação, o medo, um mundo de cogitações. Não se pensara a hipótese verdadeira - Anísio morrera no poço do elevador do edifício para o qual se dirigia. Ninguém vira nada. Era a tragédia sem testemunhas, e sobre ela pairavam todas as conjecturas e todas as interrogações. Esquecidos de haver ele próprio dito vivermos em um universo de acidente e de sorte, onde não havia lei nem justiça, muitos não admitiam haver sido uma simples fatalidade. [...] Concluiu-se haver sido um acidente. Uma armadilha do destino. (VIANA FILHO, 2008, p. 231).

E o silêncio assolou: "Uma luz apagou no Brasil: sua inteligência mais luminosa", disse Darcy Ribeiro; "Agora temos de aprender a viver sem Anísio", afirmou Péricles Madureira, ao deixar o cemitério, após o sepultamento de Anísio (VIANA FILHO, 2008).

Voltamos ao prelúdio do texto, em que Anísio, em uma carta escrita a Lobato, escreve que "[...] os sonhos não se realizam sem que primeiro se armem os andaimes. E uma construção em andaimes pede imaginação e amor para ser compreendida" (VIANA FILHO; FRAIZ, 1986, p. 104 apud NUNES, 1991, p. 33). Agora, provocamos uma indagação: faltou imaginação e amor para que toda a obra de Anísio fosse compreendida? Suas ideias foram destemidas? Seus sonhos foram construídos? A violência repeliu suas diligências em prol de uma educação mais igualitária e democrática, mas não o impediu de imaginar e acreditar que era possível construir uma escola pública com um ensino básico e de boa qualidade para todos, sem privilégios.

\section{CONSIDERAÇÕES FINAIS}

Neste artigo, abordamos alguns dos aspectos mais importantes para a compreensão da obra anisiana - sua inspiração. Esperamos que essa inspiração denominada aqui por ideia destemida ou talvez um sonho construído por ele possa nos impulsionar a acreditar em uma educação pública de fato igualitária, democrática e, sobretudo, de qualidade.

Retiramos do seu pensamento e de uma boa parte de toda a obra de Anísio que a escola vislumbrada por ele, tal como seus colaboradores pensaram e objetivaram, projetava-se como uma instituição que se assemelhava a um sonho que seria possível vivenciá-lo; esse sonho, sobretudo, deveria ser conduzido por 
uma esperança da qual a força motriz seriam as vidas que dela dependeriam. Entretanto, essa esperança depositada por Anísio em nossos sonhos ainda precisa de muito amor, imaginação e, principalmente, muitos recomeços para ir em busca da educação com a qual ele sonhou.

Anísio sonhou e, no seu sonho, viu uma escola eficiente para o povo brasileiro, e é com esse propósito que ainda lutamos por ela.

\section{REFERÊNCIAS}

BERTOLETTI, Vanessa Alves; COELHO, Marcos Pereira. Anísio Teixeira e o projeto da educação brasileira. In: JORNADA DO HISTEDBR, 11., 23 a 25 de out., 2013, Cascavel. Anais da XI Jornada do HISTEDB. Cascavel, 2013. p. 1-15.

BORTOLOTI, Karen Fernanda da Silva; CUNHA, Marcos Vinicius da. Anísio Teixeira: Pioneiro do Pragmatismo no Brasil. In: CINFE CONGRESSO INTERNACIONAL DE FILOSOFIA E EDUCAÇÃO, 5., 17-20 maio, 2010, Caxias do Sul. Anais [...]. Caxias do Sul: UCS, 2010. p. 1-8.

CAVAlIERE, Ana Maria. Anísio Teixeira e a educação integral. Revista Paidéia, Ribeirão Preto, v. 20, n. 46, p. 249-59, maio/ago. 2010.

GOUVÊA, Fernando César F. Dr. Anísio, ele pensava e executava: a trajetória de Anísio Teixeira no campo da formação de professores no Brasil (1924-1950). Revista Contemporânea de Educação, Rio de Janeiro, RJ, v. 4, n. 8 p. 447-67, 2009.

NUNES, Clarice. Anísio Teixeira. Recife: Editora Massangana, 2010. [Fundação Joaquim Nabuco].

NUNES, Clarice. Trajetória intelectual e identidade do educador Anísio Teixeira (19001971). Revista Brasileira de Estudos Pedagógicos, Brasília, v. 81, n. 197, p. 154-65, 2000.

NUNES, Clarice. Anísio Teixeira: a poesia da ação. 1991. Tese (Doutorado em Ciências Humanas: Educação) - Pontifícia Universidade Católica do Rio de Janeiro, Rio de Janeiro, 1991.

PEREIRA, Guilherme Gravina. Anísio Teixeira: o percurso de um educador destemido contra a oligarquia. Revista REBELA, Florianópolis, v. 4, n. 1, jan./abr. 2014.

SAVIANI, Demerval. História das ideias pedagógicas no Brasil. 4. ed. Campinas: Autores Associados, 2013. 
SILVA, Sandra Lara da. Anísio Teixeira: pensamento, ação e contemporaneidade na busca por uma educação democrática. In: XII Congresso Nacional de Educação: “Formação de professores, Complexidade e trabalho docente- EDUCERE, XII, 26-29 out., 2015, Curitiba. Anais [...]. Curitiba: EDUCERE, 2015.

TEIXEIRA, Anísio. Educação não é privilégio. 5. ed. Rio de Janeiro: Editora UFRJ, 1994. [Original publicado em 1957].

VIANA FILHO, Luís. Anísio Teixeira: a polêmica da educação. 3. ed. São Paulo: Editora UNESP; Salvador: EDUFBA, 2008.

\section{Sobre os autores:}

Kamila Gusatti Dias: Doutoranda em Educação pela Pontifícia Universidade Católica de Goiás. Mestrado em Educação pela Universidade Estadual de Mato Grosso do Sul (UEMS), Unidade de Paranaíba, MS. Pós-Graduação em Educação Infantil e Anos Iniciais pela Universidade de Rio Verde, e Graduação em Pedagogia- licenciatura pela mesma Universidade. Realiza pesquisas na área de História e Historiografia da Educação, com ênfase em Instituições Escolares Protestantes. É associada da Sociedade Brasileira de História da Educação (SBHE), da Associação Nacional de Pós-Graduação e Pesquisa em Educação (ANPED) e da Associação Nacional de História (ANPUH). E-mail: kamilagusatti@hotmail.com, Orcid: http://orcid.org/0000-0003-2897-7422

Kênia Guimarães Furquim Camargo: Doutora em Educação pela Pontifícia Universidade Católica de Goiás (PUCGoiás). Mestrado em Educação pela Universidade Estadual de Mato Grosso do Sul. Especialização em Educação Infantil pela Universidade de Rio Verde, especialização em Matemática Superior pela Faculdades Integradas de Patrocínio (FIP). Graduação em Matemática pela Universidade de Rio Verde. Membro do grupo de pesquisa: Educação, História, Memória e Cultura em diferentes Espaços Sociais. Desenvolve pesquisas no campo da História e Historiografia da Educação Brasileira. E-mail: keniafurquim2@hotmail.com, Orcid: http://orcid.org/0000-0002-9525-9423

Maria Zeneide Carneiro Magalhães de Almeida: Doutorado em História pela Universidade de Brasília. Mestrado em Educação Filosofia e História da Educação pela Universidade Estadual de Campinas. Graduação em Pedagogia pela Pontifícia Universidade Católica de Goiás. Atualmente é professor adjunto da Pontifícia 
Universidade Católica de Goiás. Tem experiência na área de Educação, com ênfase em História da Educação, Memória, Formação de Professores, atuando principalmente nos seguintes temas: História e Memória da Educação, Cultura Escolar, formação de professores, educação do campo, história oral e cultural, história da educação mineira (noroeste) políticas educacionais, curso de pedagogia, grande sertão mineiro, gênero, diversidade étnico-cultural e patrimônio cultural. E-mail: zeneide.cma@gmail.com, Orcid: http://orcid.org/0000-0003-2220-9932

Recebido em 12/02/2020

Aprovado em 19/02/2021 